\title{
RADIAL FLOW OF VISCOUS NON-NEWTONIAN FLUIDS BETWEEN DISKS
}

\author{
TSUNG YEN NA \\ Department of Mechanical Engineering, University of Michigan \\ Dearborn, Michigan \\ and \\ ARTHUR G. HANSEN \\ College of Engineering, Georgia Institute of Technology, \\ Atlanta, Georgia
}

\begin{abstract}
A theoretical solution is given for the laminar flow of a non-Newtonian fluid between two circular parallel disks. The fluid under consideration is assumed to obey a model recently proposed by Sisko [1] which has been checked experimentally to fit accurately the viscosity data of greases over a very wide range of shear rates. By equating to zero one of the constants in the model, the model equation reduces to the power law equation which is known to represent the behavior of a large number of non-Newtonian fluids.
\end{abstract}

\section{NOTATION}

$a, b, n$ empirical constants in the Sisko model

$h$ clearance between disks

$k_{1}, k_{2}$, two functions defined in equations (26) and (27)

$p$ pressure

$Q \quad$ flow rate

$r$ radial coordinate

$v \quad$ velocity

$z \quad$ coordinate direction perpendicular to the disk

$\bar{\tau} \quad$ shearing stress tensor

$\theta \quad$ circumferential coordinate

$\phi \quad$ a velocity function defined in equation (16)

the rate of strain tensor

Subscripts

$\begin{array}{ll}e & \text { property at the outer radius } \\ i & \text { property at the inner radius } \\ r & \text { property in the } r \text {-direction } \\ z & \text { property in the } z \text {-direction } \\ \theta & \text { property in the } \theta \text {-direction } \\ w & \text { property on the surface of the disk }\end{array}$

\section{INTRODUCTION}

RECENTLY there has been increased interest in the flow behavior of fluids which do not obey Newton's law of viscosity. A number of empirical models for the relation between stress and rate of strain for various non-Newtonian fluids have been proposed. Each model is usually adequate for describing fluid properties in a certain restricted range. In the 
present paper, a theoretical solution is given for the laminar flow of a non-Newtonian fluid between parallel circular disks where the fluid under consideration is assumed to obey a recently proposed model of Sisko [1]. Mathematically Sisko's model can be written as

$$
\overline{\bar{\tau}}=-\left\{a+b\left|\sqrt{ } \frac{1}{2}(\overline{\bar{A}}: \overline{\bar{\Delta}})\right|^{(n-1)}\right\} \overline{\bar{\Delta}}
$$

where $\overline{\bar{\tau}}$ and $\overline{\bar{\Delta}}$ are the stress tensor and the rate of deformation tensor respectively; and $a, b$ and $n$ are constants defined differently for different fluids.

There are two reasons for solving a flow problem for fluids based on Sisko's model in a geometrical configuration of this type. First, Sisko's model has been checked experimentally to fit accurately the viscosity data of various commercial greases made from petroleum oils with one of the standard thickening agents such as calcium fatty acid, lithium hydroxy stearate, sodium tallow or hydrophobic silica over a wide range of shear rate $\left(0 \cdot 04-22,000 \mathrm{sec}^{-1}\right)$ [1]. Later measurements by Sisko [2] of lithium-soap greases check the model over even a wider range of shear rate $\left(0.01-40,000 \mathrm{sec}^{-1}\right)$. Other models proposed in the literature prior to the introduction of Sisko's model cover only narrow ranges of shear rate. For example, the Powell-Eyring's model was seen to check the experimental viscosity data over the range of $10-10^{5} \mathrm{sec}^{-1}$ for the three types of greases studied by Brunstrum and Leet [3]. They also conclude that the power law model fits their data only over the limited range of $10-500 \mathrm{sec}^{-1}$. The deviations from experimental data on the other two models proposed, namely, the Bingham plastics and the three parameter Ree-Eyring models are also shown in [1]. A solution for the Sisko model will therefore yield the important relation between the flow rate and the pressure drop for radial flows between two circular disks-a geometry often met with in bearing design. Secondly, the solutions for this model may be reduced to the power law model solutions upon substituting $a=0$. Since the power law model represents the flow behavior for a large class of fluids, even the special case itself would provide justification for an analysis.

\section{ANALYSIS}

The present analysis is concerned with the steady laminar flow of non-Newtonian fluids of Sisko's model between two parallel circular disks (see Fig. 1). It is assumed that the velocities in the $\theta$ - and $z$-direction are so small compared with the velocity in the radial directions, $v_{n}$ that they may be neglected to a first approximation. With these assumptions, the basic equations become

Continuity

$$
\frac{\partial}{\partial r}\left(r v_{r}\right)=0
$$

Momentum

$$
\begin{aligned}
p v_{r} \frac{\partial v_{r}}{\partial r} & =-\frac{\partial p}{\partial r}-\left[\frac{1}{r} \frac{\partial}{\partial r}\left(r \tau_{r r}\right)-\frac{\tau_{\theta \theta}}{r}+\frac{\partial \tau_{r z}}{\partial z}\right] \\
0 & =-\frac{1}{r} \frac{\partial p}{\partial \theta} \\
0 & =-\frac{\partial p}{\partial z}-\frac{1}{r} \frac{\partial}{\partial r}\left(r \tau_{r z}\right)
\end{aligned}
$$



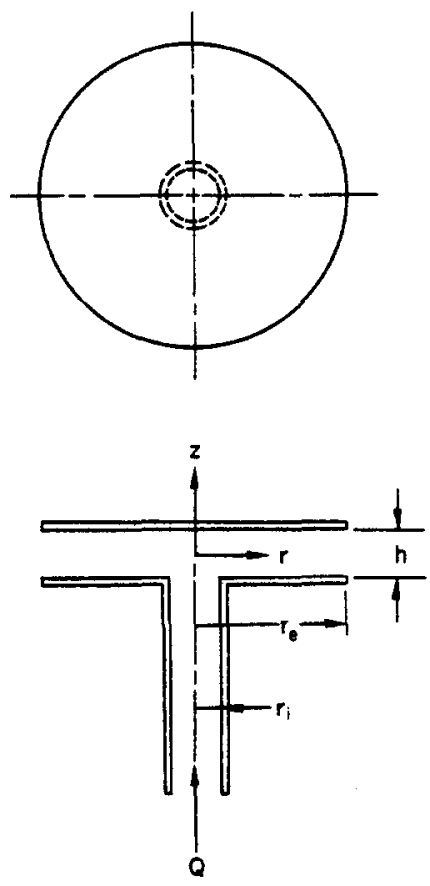

FIG. 1

The three non-vanishing component of the stress tensor are [4]

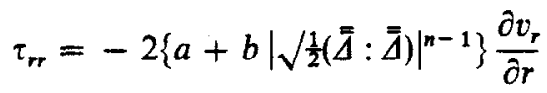

$$
\begin{aligned}
& \tau_{\theta \theta}=-2\left\{a+b\left|\sqrt{\frac{1}{2}}(\overline{\bar{\Delta}}: \overline{\bar{\Delta}})\right|^{n-1}\right\} \frac{v_{r}}{r}
\end{aligned}
$$

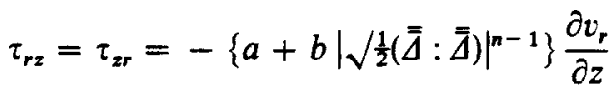

where

$$
\overline{\bar{\Delta}}=\left(\begin{array}{ccc}
2\left(\frac{\partial v_{r}}{\partial r}\right) & 0 & \left(\frac{\partial v_{r}}{\partial z}\right) \\
0 & 2\left(\frac{v_{r}}{r}\right) & 0 \\
\left(\frac{\partial v_{r}}{\partial z}\right) & 0 & 0
\end{array}\right)
$$

and

$$
\frac{1}{2}(\bar{\Delta}: \overline{\bar{\Delta}})=2\left(\frac{\partial v_{r}}{\partial r}\right)^{2}+2\left(\frac{v_{r}}{r}\right)^{2}+\left(\frac{\partial v_{r}}{\partial z}\right)^{2}
$$


As would be expected, the mathematical complexity inherent in this formulation indicates the necessity for further simplification. Specifically, consider the case in which the viscous terms predominate and the inertia term may be neglected.* The above equations are then simplified considerably. It is also assumed that the rate of change of velocity $v_{r}$ with respect to the radial direction is much smaller than its rate of change in the $z$-direction. As a result, the viscous terms can be simplified tot the forms

$$
\begin{aligned}
\tau_{r r} & =\tau_{\theta \theta} \doteq 0 \\
\tau_{r z} & =\tau_{z r} \doteq-\left\{a+b\left|\sqrt{ }\left(\frac{\partial v_{r}}{\partial z}\right)^{2}\right|^{n-1}\right\} \frac{\partial v_{r}}{\partial z} \\
& =\left\{a\left(-\frac{\partial v_{r}}{\partial z}\right)+b\left(-\frac{\partial v_{r}}{\partial z}\right)^{n}\right\}
\end{aligned}
$$

The second equal sign follows for any $n$ under the assumption that the flow is symmetrical with respect to the plane $z=0$ (see Fig. 1) so that only the upper half of the flow is considered. Under these assumptions, the basic equations become :

Continuity

$$
\frac{\partial}{\partial r}\left(r v_{r}\right)=0
$$

Momentum

$$
\begin{gathered}
\frac{\partial p}{\partial r}+\frac{\partial \tau_{r z}}{\partial z}=0 \\
\frac{1}{r} \frac{\partial p}{\partial \theta}=0 \\
\frac{\partial p}{\partial z}=0
\end{gathered}
$$

with the boundary conditions :

$$
\begin{array}{ll}
z=0: & \frac{\partial v_{r}}{\partial z}=0 \\
z=\frac{h}{2}: & v_{r}=0
\end{array}
$$

The pressure at the inner and outer radii are assumed to be $p_{i}$ and $p_{e}$ respectively.

* Ordinarily, this would be a low Reynolds number flow.

$\dagger$ From continuity, we get

$$
\frac{\partial v_{r}}{\partial r}=-\frac{v_{r}}{r}
$$

therefore the assumption of $\left|\frac{\partial v_{r}}{\partial r}\right| \ll\left|\frac{\partial v_{r}}{\partial z}\right|$ means also that $\left|\frac{v_{r}}{r}\right| \ll\left|\frac{\partial v_{r}}{\partial z}\right|$. 
From equation (12) we see that $\left(r v_{r}\right)$ is independent of $r$. Therefore, a function, $\phi(z)$, can be defined as

$$
r v_{r}=\phi(z)
$$

Equations (14) and (15) imply that $p$ is independent of $\theta$ and $z$. Therefore, equation (13) becomes

$$
\frac{\mathrm{d} p}{\mathrm{~d} r}+\frac{\partial \tau_{\mathrm{rz}}}{\partial z}=0
$$

For fluids obeying Sisko's model, the rheological behavior can be expressed by equation (11). Employing this result in equation (17), and integrating the equation with respect to $z$ and determining the constant of integration by the first boundary condition, we get

$$
\frac{\mathrm{d} p}{\mathrm{~d} r} z+a\left(-\frac{\partial v_{r}}{\partial z}\right)+b\left(-\frac{\partial v_{r}}{\partial z}\right)^{n}=0
$$

In terms of $\phi$ introduced in equation (16), equation (18) may be written

$$
\frac{\mathrm{d} p}{\mathrm{~d} r} z+\frac{a}{r}\left(-\phi^{\prime}\right)+\frac{b}{r^{n}}\left(-\phi^{\prime}\right)^{n}=0
$$

where the prime represents differentiation with respect to $z$.

Equation (19) has no non-trival solutions of $\phi^{\prime}$, except in the case of the Newtonian or power-law fluids. Therefore, no solutions for the velocity can be found for the Sisko's model. However, the relation between the flow rate, $Q$, and the pressure drop, $p_{i}-p_{e}$, can be obtained for the Sisko's model in the following manner. Equation (19) can be integrated over $r$, thus

$$
\left(p_{i}-p_{e}\right) z=a \ln \frac{r_{e}}{r_{i}}\left(-\phi^{\prime}\right)+\frac{b\left(r_{e}^{1-n}-r_{i}^{1-n}\right)}{1-n}\left(-\phi^{\prime}\right)^{n}
$$

In order to express the flow rate as a function of pressure drop, it is necessary to solve equation (20) for $\phi$ and substitute the result into the following equation:

$$
Q=2 \int_{0}^{\frac{h}{2}} 2 \pi r v_{r} \mathrm{~d} z=4 \pi \int_{0}^{\frac{h}{2}} \phi \mathrm{d} z .
$$

A closed form solution of equation (20) appears unlikely due to the power $n$ in the second term of the right-hand side of this equation. This difficulty can be overcome by a change of variables in equation (21). Integrating by parts,

$$
Q=-4 \pi \int_{0}^{\phi_{w}} z \mathrm{~d} \phi=-4 \pi \int_{0}^{\phi_{w}} z \phi^{\prime} \mathrm{d} z
$$

where $\phi_{w}$ is the value of $\phi$ evaluated at the surface of the disk, i.e. at $z \doteq h / 2$. Equation (22) is then integrated by parts again, then

$$
Q=-2 \pi\left[\frac{h^{2} \phi_{w}^{\prime}}{4}-\int_{0}^{\phi_{w}^{\prime}} z^{2} \mathrm{~d} \phi^{\prime}\right]
$$

Again, $\phi_{w}^{\prime}$ is the value of $\phi^{\prime}$ evaluated at $z=h / 2$, i.e. the surface of the disk. 
The form of equation (23) is more convenient to integrate than equation (21) since $z$ is expressed implicitly as a function of $\phi^{\prime}$ in equation (20).

Substituting equation (20) into the integral in equation (23) and carrying out the integration, a closed form expression for $Q$ is obtained as

$$
Q=2 \pi\left\{\frac{h^{2}\left(-\phi_{w}^{\prime}\right)}{4}-\frac{k_{1}{ }^{2}\left(-\phi_{w}^{\prime}\right)^{3}}{3}-\frac{2 k_{1} k_{2}\left(-\phi_{w}^{\prime}\right)^{n+2}}{n+2}-\frac{k_{2}{ }^{2}\left(-\phi_{w}^{\prime}\right)^{2 n+1}}{2 n+1}\right\}
$$

where $\phi_{w}^{\prime}$ is expressed implicitly as a function of the pressure drop in the equation

$$
\frac{\left(p_{i}-p_{e}\right) h}{2}=a \ln \frac{r_{e}}{r_{i}}\left(-\phi_{w}^{\prime}\right)+\frac{b\left(r_{e}{ }^{1-n}-r_{i}{ }^{1-n}\right)}{1-n}\left(-\phi_{w}^{\prime}\right)^{n}
$$

(obtained by putting $z=h / 2$ and $\phi^{\prime}=\phi_{w}^{\prime}$ in equation (20)). The two constants, $k_{1}$ and $k_{2}$, in equation (24) are

$$
k_{1}=\frac{a \ln \frac{r_{e}}{r_{i}}}{p_{i}-p_{e}}
$$

and

$$
k_{2}=\frac{b\left(r_{e}{ }^{1-n}-r_{i}^{1-n}\right)}{(1-n)\left(p_{i}-p_{e}\right)}
$$

respectively.

Equations (24) and (25) together give the relation between the flow rate, $Q$, and the pressure drop, $p_{i}-p_{e}$. Their relations can be computed by putting into these equations different values of $\phi_{w}^{\prime}$ and the corresponding pair of $Q$ and $P_{i}-P_{e}$ can be obtained.

Special cases

(1) Power-law model (the Ostwald-de Waele model). By putting $a=0$, the special case of the power law fluid is obtained which gives

$$
Q=\frac{4 n \pi}{2 n+1}\left\{\frac{\left(p_{i}-p_{e}\right)(1-n)}{b\left(r_{e}{ }^{1-n}-r_{i}^{1-n}\right)}\left(\frac{h}{2}\right)^{2 n+1}\right\}^{\frac{1}{n}}
$$

The velocity profile can be solved by integrating equation (20) over $z$ and substituting the result into equation (16). Thus,

$$
v_{r}=\frac{n}{(n+1) r}\left(\frac{h}{2}\right)^{\frac{n+1}{n}}\left[\frac{(1-n)\left(p_{i}-p_{e}\right)}{b\left(r_{e}^{n-1}-r_{i}^{n-1}\right)}\right]^{\frac{1}{n}}\left[1-\left(\frac{2 z}{h}\right)^{\frac{n+1}{n}}\right]
$$

(2) Newtonian fluids. This case can be obtained by either putting $b=0$ or $a=0$ and $n=1$ simultaneously in equation (11). The flow rate, $Q$, and the velocity, $v_{r}$, for this case then become

$$
Q=\frac{4 \pi\left(p_{i}-p_{e}\right)}{3 \mu \ln \frac{r_{e}}{r_{i}}}\left(\frac{h}{2}\right)^{3}
$$


and

$$
v_{r}=\frac{\left(p_{i}-p_{e}\right)}{2 \mu r \ln \frac{r_{e}}{r_{i}}}\left(\frac{h}{2}\right)^{2}\left[1-\left(\frac{2 z}{h}\right)^{2}\right]
$$

\section{NUMERICAL RESULTS AND DISCUSSIONS}

Numerical results based on the above equations have been computed and are present in Figs. 2-11. Figures 2-8 are solutions of equations (24) and (25) for "grease A" in Sisko's original investigation [1] with $a=2 \cdot 7 \mathrm{dyn}-\mathrm{sec} / \mathrm{cm}^{2}, b=1940 \mathrm{dyn} / \mathrm{cm}^{2}$ and $n=0.139$.

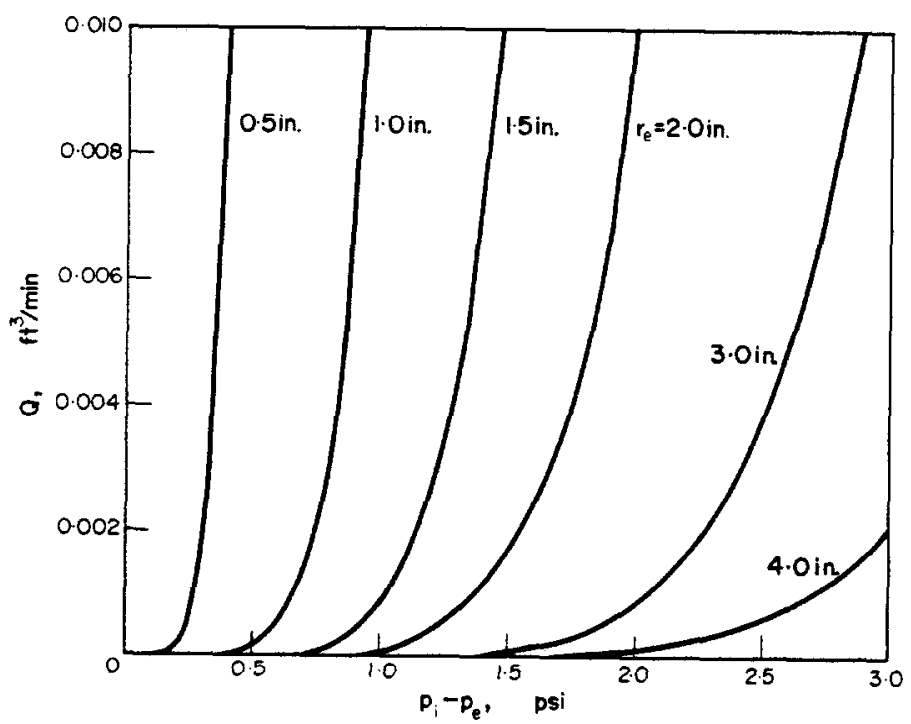

FIG. 2

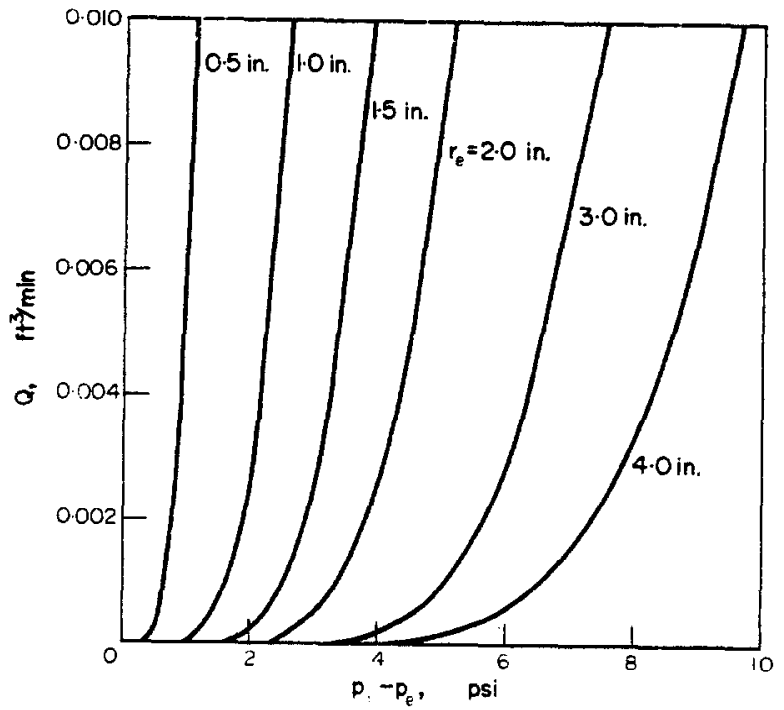

Fig. 3 


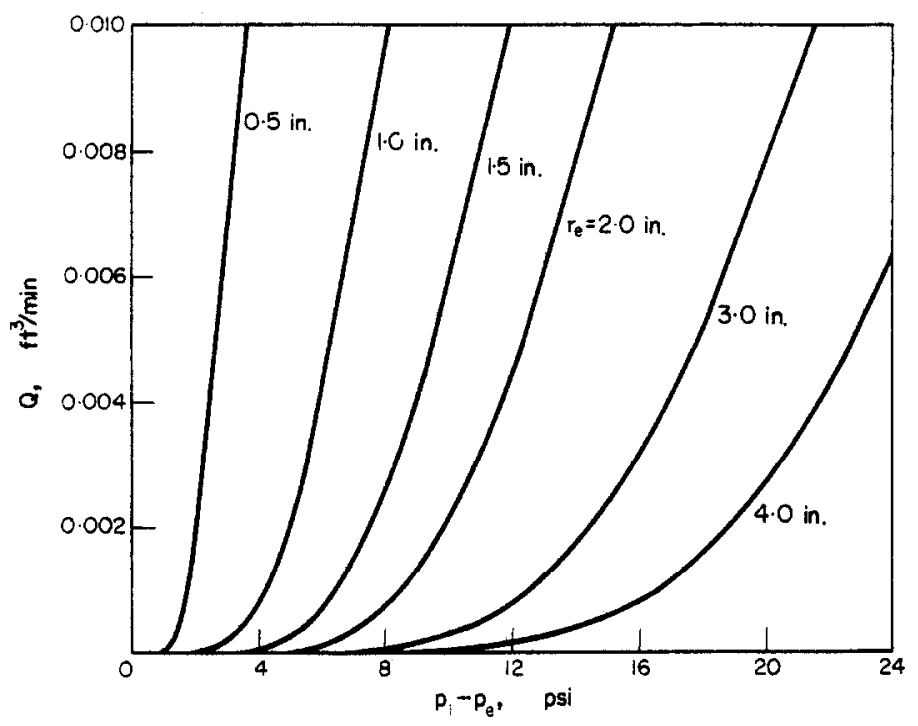

Fig. 4

The inner radius of the disk is taken to be constant at 0.2 in. Figures $2-4$ show the variation of the flow rate, $Q$, with respect to the pressure drop, $p_{i}-p_{e}$, for different values of $r_{e}$. The clearance between the disks is kept at $0.1 \mathrm{in} ., 0.05 \mathrm{in}$. and $0.025 \mathrm{in}$. in the three figures respectively. It is seen that as the flow rate increases from zero the pressure drop needed to force it through the disks increases rapidly. However, this trend does not continue.

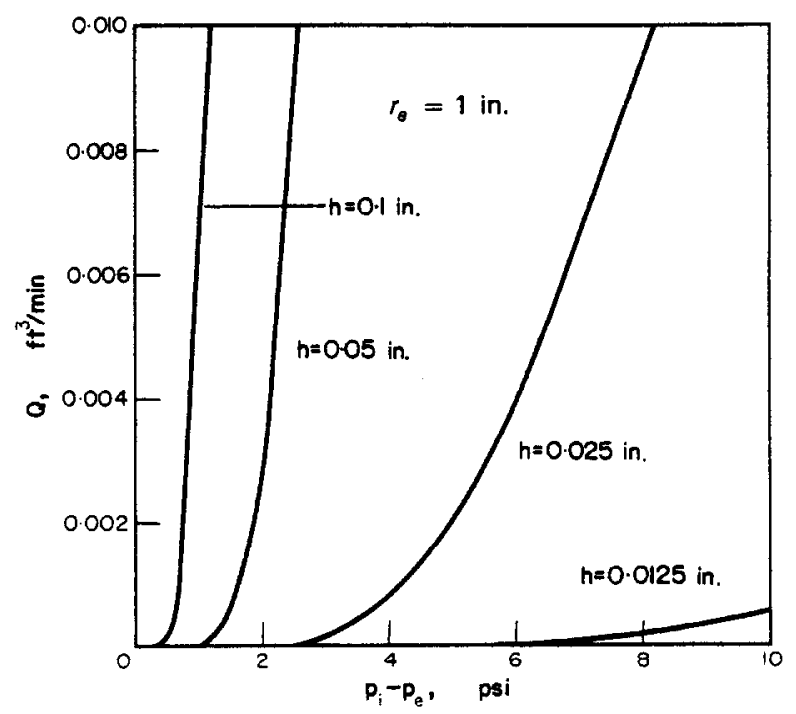

FIG. 5 


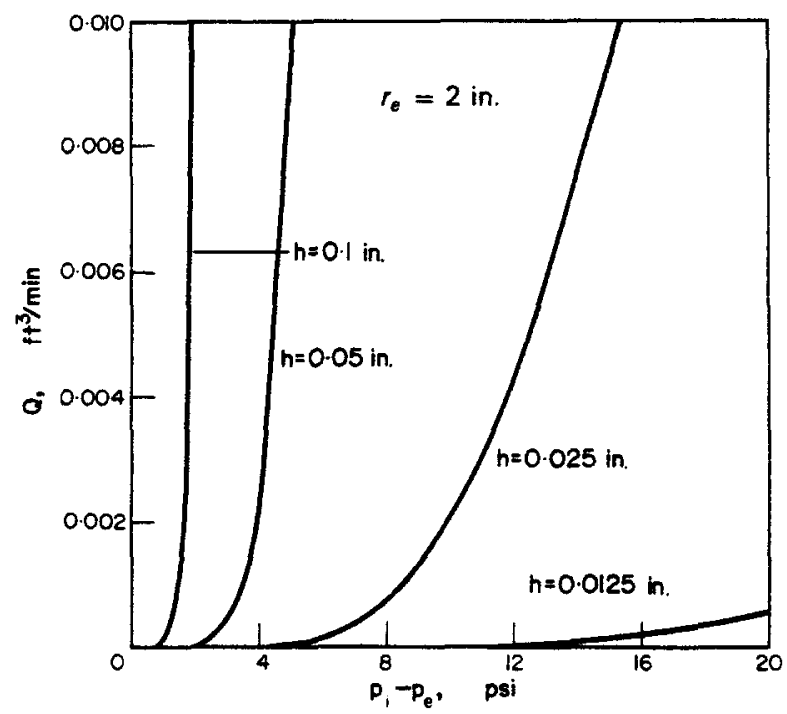

FIG. 6

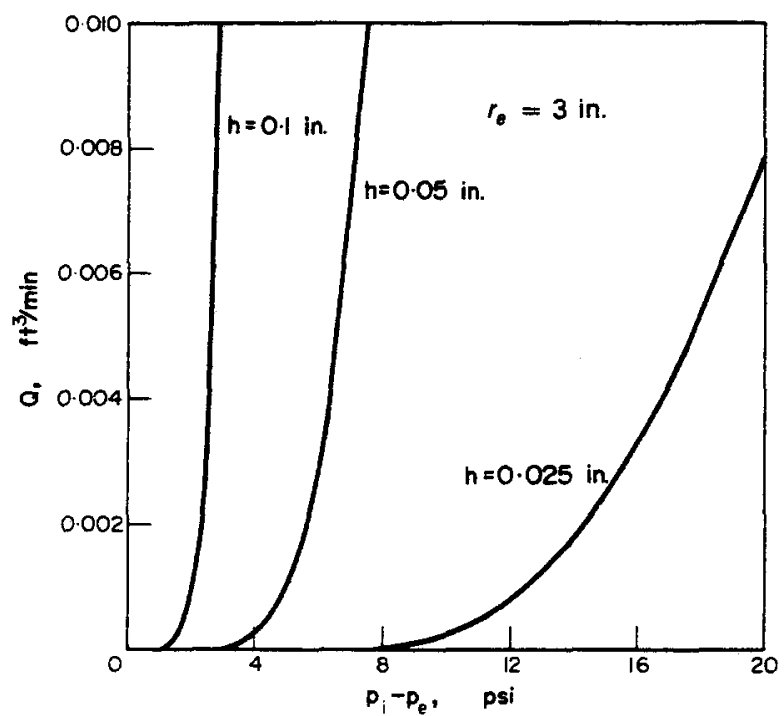

Fig. 7

Ultimately the phenomena is reversed. A large increase in the flow rate is then accompanied by a small increase in the pressure drop. This is typical of grease flow since greases have high viscosity at low shear rate and low viscosity at high shear rate. Thus one expects large resistance to flow when the flow rate, $Q$, is small. Figures 5-7 give $Q$ vs. $p_{i}-p_{e}$ with constant clearances. Each figure is plotted for a different size of disk. The same feature characterizing the rate of change of $Q$ with $\left(p_{i}-p_{e}\right)$ again shows in the figures. Figure 8 shows the pressure drop, $\left(p_{i}-p_{e}\right)$, plotted against the radial location. It shows that the pressure drop is almost linearly proportional to the radial distance. 
Equation (28) is plotted in Fig. 9 for different values of $n$. For $n<1$, the curve is qualitatively the same as in Figs. 2-7. In fact, the power law model with $n<1$ has been successful in predicting the flow of greases in certain ranges of shear rate [3]. For $n>1$, the phenomena is completely reversed and the flow offers less resistance at low shear rate but increases

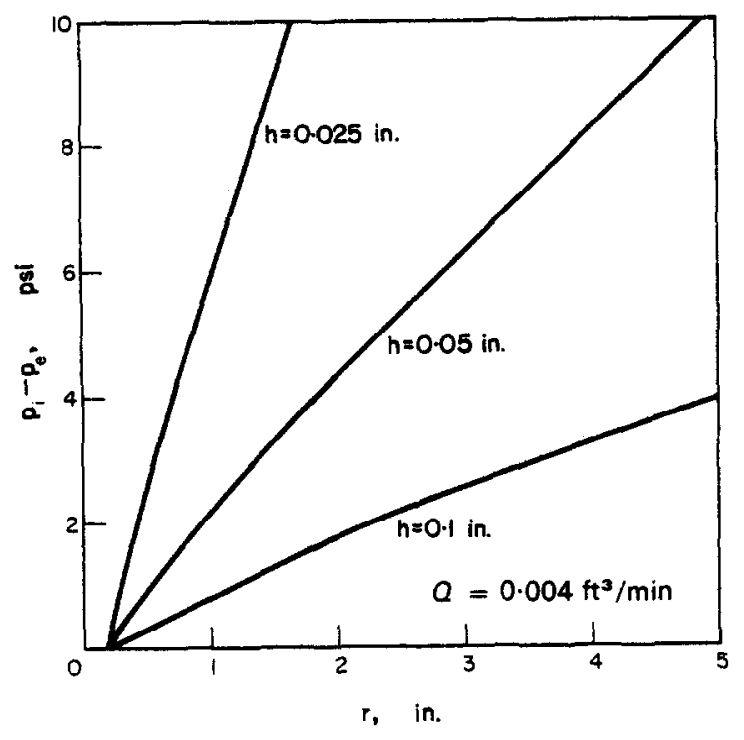

FIG. 8

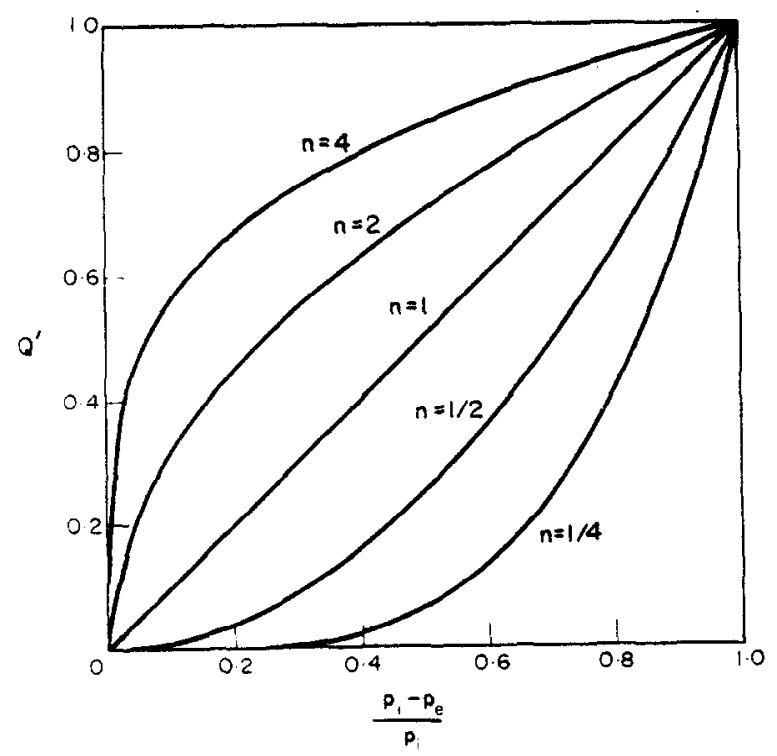

FIG. 9 
at higher shear rates. The special case of Newtonian fluids gives a linear relation between $Q$ and $\left(p_{i}-p_{e}\right)$. The dimensionless flow rate, $Q^{\prime}$, in Fig. 9 is defined from equation (28) as

$$
Q^{\prime}=\frac{(2 n+1) Q}{4 n \pi}\left\{\frac{(1-n) p_{i}}{b\left(r_{e}^{1-n}-r_{i}^{1-n}\right)}\left(\frac{h}{2}\right)^{2 n+1}\right\}^{-1 / n}
$$

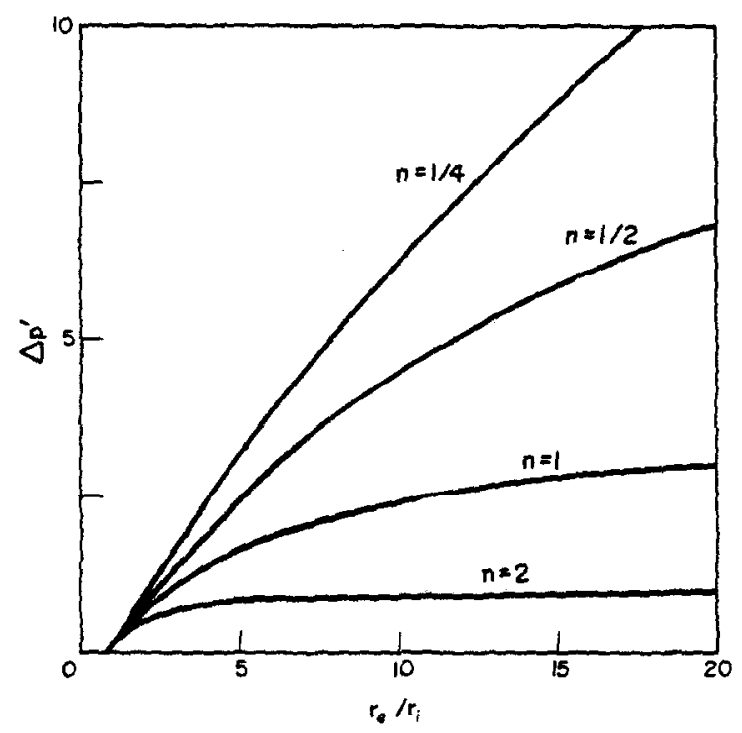

Fig. 10

The pressure distribution in a given disk are shown in Fig. 10 with the dimensionless pressure drop (of equation (28))

$$
\Delta p^{\prime}=\left\{\frac{4 n \pi}{(2 n+1) Q}\right\}^{n}\left\{\frac{\left(p_{i}-p_{e}\right)}{b r_{i}^{1-n}}\left(\frac{h}{2}\right)^{2 n+1}\right\}
$$

and the dimensionless radius, $r_{e} / r_{i}$, as coordinates. The relation between $\Delta p^{\prime}$ and $r_{e} / r_{i}$ can be found from equation (28) as

$$
\Delta p^{\prime}=\frac{1}{(1-n)}\left[\left(\frac{r_{e}}{r_{i}}\right)^{1-n}-1\right]
$$

From the special case of $n=1$

$$
\Delta p^{\prime}=\frac{4 \pi}{3 Q b}\left(\frac{h}{2}\right)^{3}\left(p_{i}-p_{e}\right)
$$

and equation (34) can be reduced to

$$
\Delta p^{\prime}=\ln \frac{r_{e}}{r_{i}}
$$


This result may also be obtained from equation (30) directly. From the figure, it is seen that the pressure drop is larger for fluids with smaller $n$. Again, for low values of $n$, the curves show the same large increase in the pressure drop as in Fig. 8.

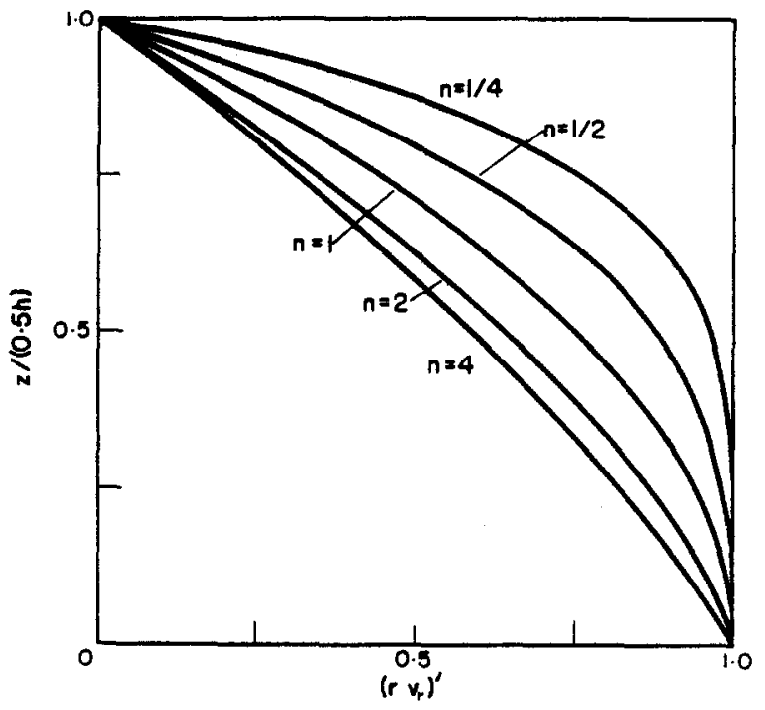

Fig. 11

Finally, the velocity profiles for power law fluids are plotted for different values of $n$ in Fig. 11. As in the case of pipe flow, small values of $n$ give flatter velocity profiles. The dimensionless form of $r_{r}$ in the figure is defined as

$$
\left(r v_{r}\right)^{\prime}=\left(r v_{r}\right) \frac{n+1}{n}\left[\left(\frac{h}{2}\right)^{n+1} \frac{(1-n)\left(p_{i}-p_{e}\right)}{b\left(r_{e}^{n-1}-r_{i}^{n-1}\right)}\right]^{-1 / n}
$$

Consequently, equation (29) can be written as

$$
\left(r v_{r}\right)^{\prime}=\left[1-\left(\frac{2 z}{b}\right)^{\frac{n+1}{n}}\right]
$$

\section{REFERENCES}

[1] A. W. Sisko, The flow of lubricating greases Ind. Engng Chem. 50, 1789-1792 (1958).

[2] A. W. Sisko, Capillary viscometer for non-Newtonian liquids J. Colloid Sci. 15, $89-96$ (1960).

[3] L. C. BRUNSTRUM and R. H. LeEt, Capillary viscometry of lubricating grease Lubric. Engng 12, 316 (1956).

[4] R. B. Bird, W. E. Stewart and E. N. Lightfoot, Transport Phenomena, p. 106. Wiley (1960). 
Résumé- On donne une solution théorique pour le flux laminaire d'un fluide non Newtonien entre deux disques circulaires parailèles. Le fluide considéré est supposé obéir à un modèle récemment proposé par Sisko [1] que l'expérience a vérifié conforme avec précision aux données de la viscosité des graisses sur une très grande étendue de contraintes. En égalant à zéro une des constantes du modèle, l'équation se réduit à une fonction puissance qui, on le sait, représente le comportement d'un grand nombre de fluides non Newtoniens.

Znsammenfassung-Eine theoretische Lösung für die laminare Strömung einer nicht-Newton'schen Flüssigkeit zwischen zwei kreisförmigen, paralielen Scheiben wird angegeben. Es wird angenommen, dass die betrachtete Flüssigkeit einem Modell foglt, das kürzlich von Sisko [1] vorgeschlagen wurde und das im Experiment fähig gewesen war, die Viskositätswerke von Schmiermitteln über einen sehr weiten Schubraten berich recht genau wiederzugeben. Wird in dem Modell eine der Konstanten gleich null gesetzt, do wird die Modellgleichung zu der Potenzgesetzgleichung reduziert, welche bekanntlich das verhalten einer grossen Zahl von nicht-Newton'schen Flüssigkeiten beschreibt.

\footnotetext{
Абстрякт-Приводится теоретическое решение проблемы ламинарного течения неньютоновской жидкости между двумя кругльми параллельными дисками. ІІредлопожено, что рассматриваемая жидкость подчиняется закону справедливому для модели предложеннои в последнее время Сиско [1] и по әкспериментам об̆ладающей точно данными жировых смазок в очень широком диапазоне скоростей сдвига. Приравненне нулю одной из нонстант модели, приводит уравпепие модели к виду уравнения степенного авкона, о нотором иавестно, что оно описывает поведение многих не-ньютоновских жидкостей.
} 